\title{
Perfil aromático e qualidade química da carne de caprinos Saanen alimentados com diferentes níveis de concentrado
}

\section{Marta Suely Madruga ${ }^{1}$, Mércia de Sousa Galvão ${ }^{2}$, Roberto Germano Costa ${ }^{3}$, Sandra Elisabeth Santiago Beltrão ${ }^{4}$, Neube Michel dos Santos ${ }^{4}$, Fernanda Monteiro de Carvalho ${ }^{5}$, Vaneska Delgado Viaro 5}

${ }^{1}$ Departamento de Tecnologia Química e de Alimentos, Universidade Federal da Paraíba (DTQA/UFPB), Campus I, João Pessoa/PB, CEP: 59.059-900.

2 Pesquisador DTQA/UFPB.

${ }^{3}$ Centro de Formação de Tecnólogos da UFPB, Bananeiras/PB.

${ }^{4}$ Programa de Doutorado Integrado em Zootecnia da UFPB, Areia/PB.

${ }^{5}$ Bolsista PIBIC (CNPq/UFPB).

RESUMO - Objetivou-se com este trabalho avaliar o efeito do nível de concentrado na dieta sobre a qualidade da carne de caprinos machos Saanen não-castrados. Foram utilizados 15 cabritos com peso vivo inicial de $16 \pm 0,3 \mathrm{~kg}$ e 4 meses de idade alimentados com dietas formuladas com 80, 65 ou 50\% de concentrado até que atingissem $22 \mathrm{~kg}$ de peso vivo médio final. As rações foram formuladas para promover ganho de peso de $150 \mathrm{~g} / \mathrm{animal} / \mathrm{dia}$. Nas 15 paletas caprinas, foram avaliados a composição centesimal, a cor, a textura, o pH, o perfil lipídico e o perfil de componentes voláteis. Os níveis de concentrado e volumoso utilizados na alimentação dos caprinos Saanen não influenciaram os parâmetros químicos e físico-químicos de umidade, cinzas, proteínas, colesterol, fosfolipídios, pH, Aw, a*, b*, L* da carne. No entanto, a concentração de gordura, os percentuais de ácidos graxos insaturados (mono e poli) e a textura da carne diferiram significativamente entre os níveis de concentrado usados. Tanto na análise qualitativa quanto na quantitativa de componentes voláteis, o extrato da carne de caprinos alimentados com 50\% de concentrado apresentou melhor qualidade aromática. A relação 50:50 volumoso:concentrado foi a mais viável para a alimentação de caprinos machos Saanen para abate aos $22 \mathrm{~kg}$ de peso vivo, considerando os aspectos de redução de custo e qualidade química e aromática da carne caprina produzida.

Palavras-chave: composição centesimal, componentes lipídicos, alimentação, carne caprina, voláteis

\section{Aroma profile and chemical quality of goat Saanen meat fed with different levels of concentrate}

\begin{abstract}
The objective of this work was to evaluate the effect of the levels concentrate of the diet on meat quality of no castrated male kid Saanen goats. Fifteen male goat with initial $16 \pm 0.3 \mathrm{~kg}$ BW and four months old were fed diets formulated with 80,65 e 50 of concentrate up to the animals reached a final a $22 \mathrm{~kg} \mathrm{BW}$. The rations were formulated to promote a weight gain of $150 \mathrm{~g} / \mathrm{anim}$.day. Centesimal composition, colour, texture, lipid and volatile components profile were evaluated in fifteen goat shoulders. The concentrate and forage levels used in the feeding of male kid Saanen goats did not influenced the chemical and physical-chemical parameters of humidity, ashes, proteins, cholesterol, phospholipids, $\mathrm{pH}, \mathrm{Aw}, \mathrm{a}^{*}, \mathrm{~b}^{*}, \mathrm{~L}^{*}$ of goat meat. However, the concentration of fat, the percentages of unsaturated fatty acid (mono and poly) and the texture of meat were affected by the used concentrate levels. In both qualitative and quantitative of volatile components analysis, the extract of the goat meat fed with $50 \%$ of concentrate showed better aromatic quality. The use of 50:50 forage to concentre ratio was most viable for the feeding male kid Saanen goats slaughtered at $22 \mathrm{~kg}$ BW, considering both the aspects of reducing cost of production and chemical and aromatic quality of the produced goat meat.
\end{abstract}

Key Words: chemical composition, fat components, feeding, goat meat, volatiles

\section{Introdução}

A carne caprina tem grande potencial de consumo, em razão de seu valor nutritivo e de suas características, como o reduzido acúmulo de gordura nos tecidos, o que lhe confere o conceito de carne magra e a torna uma opção para o exigente público consumidor (Madruga, 2004). 
Entre as raças caprinas com aptidão para produção de leite, a Saanen, originária da Suíça, é a mais conhecida no mundo e tem contribuído significativamente para o melhoramento de diversos rebanhos caprinos leiteiros. Além da capacidade dessa raça em produzir leite, sua carne é consideravelmente apreciada.

Atualmente, existe uma preocupação crescente com o destino dos cabritos nascidos em um rebanho leiteiro. Normalmente, esses animais são vendidos ou abatidos sem o desenvolvimento adequado de suas carcaças, necessário para que a carne tenha qualidade desejável (Pereira et al., 2005).

Independentemente da produção (carne ou leite), é fundamental otimizar a criação dos cabritos para viabilizar a maior rentabilidade na atividade. A limitação de trabalhos enfocando aspectos da qualidade da carne de caprinos tem impulsionado as pesquisas nesta área. A qualidade da carcaça e da carne é influenciada por fatores como a dieta (Madruga, 2003). Logicamente, o estudo desta fonte de variação é necessário para garantir e oferecer carne de boa qualidade ao mercado.

A maximização do uso de concentrado em dietas para ruminantes, além de promover aumento nos custos de produção, eleva as possibilidades de ocorrência de distúrbios fisiológicos nos animais (Alves et al., 2003). Por outro lado, deve-se avaliar o quanto a redução dos níveis de concentrado na ração de caprinos pode prejudicar a qualidade da carne desses animais.

A determinação de um nível ótimo de concentrado que proporcione carcaça e carne de boa qualidade a partir de melhor relação custo/benefício é uma forma de o produtor obter maior lucratividade. Resende (1994) recomenda que, para melhorar o desempenho e os rendimentos de carcaça, é indispensável o fornecimento de relação volumoso:concentrado adequada com o objetivo de maximizar o desempenho animal.

Raças caprinas leiteiras como a Saanen geralmente apresentam menor cobertura muscular em comparação às raças produtoras de carne. No entanto, quando manejados adequadamente, podem atingir ganhos de peso satisfatórios e boa conformação da carcaça (Pereira Filho et al., 2005).

Apesar da vasta literatura sobre o efeito da alimentação nas características de carcaça de caprinos, poucos dados estão disponíveis sobre o efeito da relação volumoso:concentrado na qualidade química e aromática da carne caprina, especialmente de cabritos da raça Saanen. Com o intuito de esclarecer esses questionamentos, objetivou-se com este trabalho avaliar o efeito de diferentes níveis de concentrado e volumoso sobre a qualidade química e o perfil aromático da carne de caprinos machos Saanen não-castrados.

\section{Material e Métodos}

O estudo foi realizado no Setor de Caprinocultura do Centro de Formação de Tecnólogos da Universidade Federal da Paraíba utilizando-se 15 cabritos Saanen não-castrados, com peso vivo inicial de $16 \pm 0,3 \mathrm{~kg}$ e 4 meses de idade. Os animais foram alojados em baias individuais de $1,3 \mathrm{~m}^{2}$, com piso ripado, providas de comedouro e bebedouro, e, no início do período experimental, receberam uma dose de vermífugo e complexo vitamínico A, D e E, de acordo com recomendações do laboratório fornecedor.

Os tratamentos consistiram de três dietas, formuladas com 20, 35 ou $50 \%$ de concentrado. As rações foram compostas de feno de capim-elefante, milho, farelo de soja, melaço de cana-de-açúcar em pó, óleo de soja e núcleo mineral em quantidades calculadas para atender às exigências em proteína bruta e energia metabolizável, de modo que permitisse aos animais ganhos de $150 \mathrm{~g} / \mathrm{animal} / \mathrm{dia}$, de acordo com as recomendações do AFRC (1998). O volumoso, fenado e moído, foi misturado manualmente ao concentrado e fornecido pela manhã aos animais, de modo a permitir sobra de $10 \%$. Os animais (cinco de cada tratamento) foram pesados semanalmente para controle do desenvolvimento corporal e, ao atingirem peso médio final de $22 \mathrm{~kg}$, foram abatidos segundo recomendações vigentes no RIISPOA (BRASIL, 1997).

As carcaças foram resfriadas em câmara frigorífica a temperatura inferior a $5^{\circ} \mathrm{C}$ por 24 horas. Durante esse período, realizou-se o controle de resfriamento da carcaça por meio de determinações da temperatura, obtida por incisão no músculo Longissimus dorsi, entre a 12a e 13a vértebras, de um eletrodo de um potenciômetro digital portátil (TESTO 205) acoplado com sensor de temperatura, com sensibilidade de $0,1^{\circ} \mathrm{C}$.

As 15 paletas obtidas durante a desossa das carcaças foram acondicionadas em sacos plásticos e armazenadas em freezer a $-18^{\circ} \mathrm{C}$ por um período não superior a dois meses até que os estudos fossem realizados. As paletas dos cabritos foram descongeladas em geladeira convencional por 24 horas e, em seguida, foram desossadas para retirada dos ossos e da gordura de cobertura. Para as análises químicas e de voláteis, diversos pedaços da paleta foram amostrados e triturados em liquidificador até a obtenção de uma pasta homogênea. Diferentes pedaços de $5 \mathrm{~cm}^{3}$ de cada paleta foram acondicionados em sacos plásticos até a realização das análises físicas e fisico-químicas, quando foram cortados (análises de cor e de textura) ou triturados (pH e Aw) segundo as metodologias pertinentes.

Os teores de umidade, cinzas e proteínas foram quantificados segundo metodologia descrita pela AOAC 
(2000). A gordura foi extraída pelo método de Folch et al. (1957).

As dosagens dos componentes lipídicos constaram, além da dosagem dos lipídios totais, da determinação do colesterol total (Bohac et al., 1988), dos fosfolipídios totais (Egan et al., 1981) e do perfil de ácidos graxos (Madruga et al., 2006b; Madruga et al., 2001).

As análises de cor e textura, medida como força de cisalhamento, foram determinadas na carne crua. Em média, três amostras foram retiradas por paleta (cortadas em fatias de $2 \mathrm{~cm}$ de espessura) e expostas ao ar atmosférico por 30 minutos (tempo necessário para que ocorresse a reação da mioglobina do músculo com o oxigênio do ar formando a oximioglobina, principal pigmento que determina a cor vermelho brilhante da carne). Depois desse período, foi realizada a leitura com o colorímetro Minolta Chroma Meter utilizando-se o sistema de avaliação CIELAB, no qual L* corresponde ao teor de luminosidade; $\mathrm{b}^{*}$ ao teor de amarelo; e a* ao teor de vermelho, segundo metodologia utilizada por Abularach et al. (1998).

As análises objetivas de textura (força de cisalhamento) foram medidas com aparelho "Warner Bratzler Shear Force” (5-Speed Drillpress, Model n ${ }^{\circ}$ ZJ4110, Chuck 1/2", Spindle J2513, Motor 1/3 HP), segundo metodologia de Duckett et al. (1998). A atividade de água foi determinada em aparelho AquaLab CX2 e o pH em peagâmetro Digimed PS3.

Os voláteis da carne foram extraídos utilizando-se a técnica de extração/destilação simultânea de voláteis em aparelho de Likens \& Nickerson (1964), seguida de separação e identificação em CG-EM. Todas as extrações foram realizadas em triplicatas.

Aproximadamente $200 \mathrm{~g}$ de carne foram cozidos em forno convencional por 55 minutos (Madruga et al., 2000). Depois de resfriada, a carne cozida foi transferida para o balão de extração e adicionada a $500 \mathrm{~mL}$ de água destilada. Em seguida, realizou-se a agitação. Trinta mililitros (30 mL) de uma mistura contendo éter etílico:pentano na proporção de 3:27 (v/v) foram transferidos para o balão de solvente com capacidade de $50 \mathrm{~mL}$. Os conteúdos de ambos os frascos foram aquecidos e submetidos ao processo de extração/destilação durante 2 horas. Após o processo de extração, o extrato aromático foi resfriado a temperatura ambiente, transferido para o aparelho de "Kuderna-Danish" e concentrado em banho-maria a $40^{\circ} \mathrm{C}$ até volume final de 3 a $5 \mathrm{~mL}$.

Os extratos da carne caprina cozida foram analisados em CG-EM utilizando-se um detector de espectrometria de massa - HP 5972, acoplado a um cromatográfo a gás - HP
5890 ligado a uma "workstation” - HP 59970 (versão 3.2) (Hewlett-Packard, Bracknell, Bershire, UK). Um injetor tipo “split-splitless" mantido a $200^{\circ} \mathrm{C}$ foi utilizado para a introdução de $1 \mathrm{~mL}$ do extrato caprino em uma coluna capilar de sílica fundida BPX5, com $50 \mathrm{~m} \times 0,32 \mathrm{~mm}$ (d.i.) $\times 0.5 \mathrm{~mm}$ de filme da fase líquida (J\&W Scientific Inc). A temperatura inicial da coluna foi de $40^{\circ} \mathrm{C}$; após 5 minutos da injeção da amostra, a temperatura da coluna foi aumentada para $60^{\circ} \mathrm{C}$ a uma razão de $20^{\circ} \mathrm{C} /$ minuto e mantida nesta temperatura por 5 minutos. Finalmente, programou-se um novo aumento na temperatura da coluna utilizando-se uma razão de $4^{\circ} \mathrm{C} /$ minuto até a temperatura final de $250^{\circ} \mathrm{C}$, mantendo-se a coluna nesta temperatura por mais 10 minutos. Uma solução padrão de n-alcanos homólogos $\left(\mathrm{C}_{6}-\mathrm{C}_{20}\right)$ foi analisada diariamente, antes das análises dos extratos da carne, objetivando-se verificar as condições analíticas do equipamento, juntamente com o cálculo posterior do Índice de Retenção Linear (IRL) dos voláteis, utilizado na identificação dos compostos aromáticos.

Na identificação dos voláteis, utilizou-se, além do IRL, o banco de espectros da própria livraria do CG-EM para comparação dos espectros dos voláteis dos extratos da carne caprina aos espectros de referência (Anon, 1983). A quantificação dos voláteis foi obtida por meio da integração dos espectros de massa dos voláteis identificados.

O delineamento experimental utilizado foi o inteiramente casualizado com três tratamentos e cinco repetições. Os dados foram analisados por meio do SAS (1985) e submetidos à análise de variância a 5\% de probabilidade.

\section{Resultados e Discussão}

Os teores de umidade, cinzas e proteínas da carne (Tabela 1) não diferiram estatisticamente entre as dietas. No entanto, os percentuais de lipídios foram influenciados pelas relações volumoso:concentrado, uma vez que a maior concentração foi observada na carne dos animais alimentados com a dieta com $50 \%$ de concentrado. O acréscimo no teor de gordura na carne desses animais está relacionado à maior idade de abate a que foram submetidos. Sabe-se que o tecido adiposo é o último a ser depositado na carcaça do animal (Hedrick et al., 1994). Paralelamente, observou-se decréscimo no teor de lipídios com a diminuição do percentual de concentrado da ração.

Atti et al. (2004) compararam a qualidade da carne de caprinos da Tunisia alimentados com dietas com três níveis protéicos e abatidos com mesma idade e observaram que a carne de animais alimentados com nível protéico médio (130 g/kg de matéria seca) apresentou maior teor de proteína 
Tabela 1 - Composição química e físico-química da carne de cabritos Saanen alimentados com dietas com três níveis de concentrado

\begin{tabular}{|c|c|c|c|}
\hline \multirow[t]{2}{*}{ Componente $^{1}$} & \multicolumn{3}{|c|}{ Nível de concentrado $(\%)^{2}$} \\
\hline & 80 & 65 & 50 \\
\hline Umidade (g/100 g) & $70,71 \mathrm{a} \pm 2,53$ & $72,04 a \pm 1,93$ & $70,14 a \pm 3,95$ \\
\hline Cinzas (g/100 g) & $1,25 a \pm 0,13$ & $1,18 \mathrm{a} \pm 0,04$ & $1,12 \mathrm{a} \pm 0,05$ \\
\hline Proteínas (g/100g) & $20,92 \mathrm{a} \pm 1,05$ & $20,35 \mathrm{a} \pm 1,49$ & $19,53 \mathrm{a} \pm 1,77$ \\
\hline Lipídios（g/100g) & $7,07 a b \pm 2,30$ & $6,01 b \pm 1,88$ & $8,52 a \pm 3,16$ \\
\hline Colesterol (mg/100 g) & $76,05 a \pm 5,88$ & $75,57 a \pm 6,35$ & $66,96 a \pm 7,01$ \\
\hline Fosfolipídios (mg/100 g) & $61,70 a \pm 5,95$ & $57,26 a \pm 6,95$ & $63,29 a \pm 7,50$ \\
\hline Textura $\left(\mathrm{kgf} / \mathrm{cm}^{2}\right)$ & $6,78 b \pm 0,55$ & $7,56 \mathrm{ab} \pm 0,21$ & $8,38 \mathrm{a} \pm 0,34$ \\
\hline $\mathrm{pH}$ & $6,20 a \pm 0,14$ & $6,15 a \pm 0,18$ & $6,20 a \pm 0,31$ \\
\hline Aw & $0,993 \mathrm{a} \pm 0,0019$ & $0,992 \mathrm{a} \pm 0,03$ & $0,994 \mathrm{a} \pm 0,002$ \\
\hline $\mathrm{L}^{*}$ & $40,1 \mathrm{a} \pm 0,51$ & $40,1 \mathrm{a} \pm 0,70$ & $40,5 \mathrm{a} \pm 0,68$ \\
\hline$a^{*}$ & $14,92 \mathrm{a} \pm 0,52$ & $15,72 \mathrm{a} \pm 0,30$ & $16,74 a \pm 0,36$ \\
\hline $\mathrm{b}^{*}$ & $7,56 a \pm 0,29$ & $7,80 \mathrm{a} \pm 0,78$ & $8,34 a \pm 0,33$ \\
\hline
\end{tabular}

e menor percentual de lipídios em comparação à de animais alimentados com nível protéico alto (160g/kg de MS).

As médias de umidade, cinzas e proteínas encontradas nesta pesquisa foram similares aos valores obtidos por Madruga et al. (1999) na carne de mestiços Saanen machos não-castrados abatidos com 220 dias de idade. Os resultados encontrados nesta pesquisa para composição centesimal da carne foram semelhantes aos obtidos por Arruda (2003) em cabritos Saanen abatidos com 20 kg. Foram similares também aos dados de composição encontrados por Kesava Rao et al. (2003), Mioc et al. (2001), Nassu et al. (2002) e Madruga et al. (2006a) em carne caprina de outras raças.

Os percentuais de fosfolipídios e colesterol não foram influenciados pelas relações volumoso:concentrado, embora as maiores concentrações de colesterol, em valores absolutos, tenham sido encontradas na carne dos cabritos alimentados com $80 \%$ de concentrado (76,05 mg/100 g). Esses níveis de colesterol estão de acordo com os valores obtidos por Madruga (2003) em carne caprina de animais nordestinos pesquisados sob a influência de diversos fatores (idade de abate, castração, sistema de terminação, genótipos). Os valores de fosfolipídios foram relativamente superiores aos relacionados na literatura para carne caprina (Madruga et al., 2006a).

Dos quatro parâmetros analisados apenas a textura sofreu influência significativa dos níveis de concentrado utilizados na alimentação dos caprinos (Tabela 1). O aumento dos níveis de concentrado na dieta dos animais ocasionou aumento na textura e, considerando a escala de dureza descrita por Bickerstaffe et al. (1997), que classificaram carne macia com valores de força de cisalhamento de até $8 \mathrm{kgf} / \mathrm{cm}^{2}$, aceitável de 8 a $11 \mathrm{kgf} / \mathrm{cm}^{2}$ e dura acima de $11 \mathrm{kgf} / \mathrm{cm}^{2}$, pode-se afirmar que a carne analisada caracte- rizou-se como macia. Ressalta-se que a carne dos animais alimentados com $50 \%$ de concentrado pode ser classificada como de dureza aceitável por apresentar força de cisalhamento de 8 a $11 \mathrm{kgf} / \mathrm{cm}^{2}$. A maior forca de cisalhamento na carne dos animais alimentados com $50 \%$ de concentrado está relacionada ao aumento na idade de abate. Maior idade de abate resulta em aumento das ligações cruzadas das proteínas miofibrilares e do colágeno (Hedrick et al., 1994).

Observando os parâmetros de coloração da carne (L*, $\left.a^{*}, b^{*}\right)$, conclui-se que não houve diferenças nas concentrações de mioglobina no músculo dos animais. Apesar de não ter sido detectada variação na intensidade dos parâmetros $a^{*}$ e $b^{*}$, houve uma tendência de aumento desses parâmetros com o decréscimo dos níveis de concentrado na alimentação. Conseqüentemente, a carne dos animais alimentados com 50\% de concentrado apresentou-se mais amarela, fato justificado pelo seu maior teor de gordura. Segundo Madruga (2004), valores de b* em carnes com maior pontuação indicam que as tonalidades de vermelho estão mais próximas da região do amarelo, diferentemente de valores menores, que indicam cor vermelha mais próxima da região do cinza. Resultados superiores foram encontrados por Arruda (2003), que, pesquisando a qualidade da carne de cabritos Saanen abatidos com $20 \mathrm{~kg}$, reportou valores de $a *(19,58)$ e b* $(14,25)$.

Os valores de pH estão de acordo com as faixas de variação reportadas na literatura para carne caprina, no entanto, foram superiores aos relatados para outras espécies, como bovina e suína (Hedrick et al., 1994). Madruga (2004) afirmou que o $\mathrm{pH}$ final da carne caprina apresenta variação de 5,80 a 6,99, resultando em carne com coloração vermelho-escura e maior capacidade de retenção de água. Zapata et al. (2003) verificaram valores de pH final da 
carne de caprinos do Nordeste de 5,81 a 6,37. Os valores de Aw, como eram esperados, foram bastante elevados e próximos de 0,99 e não foram afetados pelo nível de concentrado da dieta.

No perfil de ácidos graxos da carne, foram identificados dez ácidos graxos saturados, seis monoinsaturados e dois poliinsaturados (Tabela 2). Os principais ácidos graxos foram o oléico (44,84 a 48,24\%), o palmítico (16,99 a 18,63\%) e o esteárico (18,35 a 20,75\%), o que está de acordo com a literatura internacional (Banskalieva et al., 2000).

Os ácidos oléico e palmítico da carne, predominantes nos animais dos três sistemas de alimentação, diferiram significativamente entre as dietas. Tanto as concentrações desses ácidos quanto as de gordura na carne dos animais alimentados com $65 \%$ de concentrado (44,84 e 16,99\%) foram inferiores $(\mathrm{P}<0,05)$ às obtidas nos animais alimentados com $80 \%$ (48,24 e 18,41\%) e com 50\% de concentrado (46,92\% e 18,63\%). Madruga et al. (2001) determinaram o ácido oléico como o principal componente do perfil de ácidos graxos da carne de caprinos mestiços Saanen nãocastrados abatidos aos 220 dias de idade.

O decréscimo dos níveis de concentrado na dieta dos caprinos determinou variação significativa $(P<0,05)$ nos percentuais totais dos ácidos graxos mono e poliinsaturados, mas não afetou os percentuais dos ácidos graxos saturados. A carne de cabritos alimentados com 50\% de concentrado apresentou percentuais totais intermediários de ácidos graxos monoinsaturados (51,34\%), no entanto, também apresentou percentuais mais baixos dos ácidos graxos poliinsaturados (4,52\%). Os percentuais dos ácidos graxos saturados e insaturados na carne caprina estão de acordo com os obtidos em outros trabalhos (Todaro et al., 2006; Kesava Rao et al., 2003; Matsouka et al., 1997; Park \& Washington, 1993).

Considerando que a concentração plasmática de colesterol é influenciada pela composição de ácidos graxos da dieta e, sabendo-se que o ácido graxo oléico (C18:1) diminui o nível de colesterol sanguíneo (Rhee, 1992), observou-se que a carne de caprinos alimentados com $50 \%$ de concentrado, com concentração de C18:1 de 46,92\%, foi mais saudável que a obtida com o fornecimento de $65 \%$ de concentrado (44,84\%).

Conclui-se, pelas relações AGI/AGS e AGPI/AGS, que a qualidade lipídica da carne caprina não foi influenciada pelos níveis de concentrado. Os valores de 1,20 a 1,39 encontrados para a relação AGI/AGS foram semelhantes

Tabela 2 - Médias das áreas percentuais dos picos de ácidos graxos da carne de cabritos Saanen alimentados com diferentes níveis concentrado

\begin{tabular}{|c|c|c|c|c|}
\hline \multirow[b]{2}{*}{ Ácido graxo $^{1}$} & \multirow[b]{2}{*}{ Nomenclatura } & \multicolumn{3}{|c|}{ Nível de concentrado (\%) } \\
\hline & & 80 & 65 & 50 \\
\hline Saturados & & $41,75 a \pm 1,20$ & $45,70 \mathrm{a} \pm 2,60$ & $44,13 \mathrm{a} \pm 1,46$ \\
\hline C 6:0 & Ácido capróico & $0,14 a \pm 0,03$ & $0,14 a \pm 0,03$ & $0,09 a \pm 0,02$ \\
\hline C 8:0 & Ácido caprílico & $0,10 \mathrm{~b} \pm 0,03$ & $0,15 a \pm 0,02$ & $0,06 \mathrm{~b} \pm 0,02$ \\
\hline C $10: 0$ & Ácido cáprico & $0,05 b \pm 0,03$ & $2,84 a \pm 0,59$ & $0,07 b \pm 0,01$ \\
\hline C $12: 0$ & Ácido láurico & $0,08 \mathrm{~b} \pm 0,02$ & $3,72 \mathrm{a} \pm 0,78$ & $0,12 b \pm 0,05$ \\
\hline C $14: 0$ & Ácido mirístico & $1,68 \mathrm{a} \pm 0,29$ & $1,64 \mathrm{a} \pm 0,37$ & $1,89 a \pm 0,07$ \\
\hline C $15: 0$ & Ácido pentadecanóico & $0,52 \mathrm{a} \pm 0,07$ & $0,45 a \pm 0,10$ & $0,54 a \pm 0,03$ \\
\hline C $16: 0$ & Ácido palmítico & $18,41 \mathrm{a} \pm 0,60$ & $16,99 b \pm 0,99$ & $18,63 a \pm 0,26$ \\
\hline C $17: 0$ & Ácido margárico & $1,29 a \pm 0,15$ & $1,16 \mathrm{a} \pm 0,14$ & $1,60 \mathrm{a} \pm 0,37$ \\
\hline C $18: 0$ & Ácido esteárico & $18,62 \mathrm{a} \pm 1,53$ & $18,35 a \pm 1,12$ & $20,75 a \pm 1,34$ \\
\hline C $20: 0$ & Ácido araquídico & $0,85 a \pm 0,48$ & $0,23 b \pm 0,09$ & $0,37 a, b \pm 0,11$ \\
\hline Monoinsaturados & & $52,85 a \pm 2,12$ & $48,90 \mathrm{~b} \pm 1,58$ & $51,34 a, b \pm 1,60$ \\
\hline C $14: 1$ & Ácido miristoleico & $0,19 a \pm 0,02$ & $0,25 a \pm 0,20$ & $0,11 \mathrm{a} \pm 0,04$ \\
\hline C $15: 1$ & Ácido pentadecenóico & $0,39 a \pm 0,04$ & $0,33 a \pm 0,08$ & $0,38 \mathrm{a} \pm 0,15$ \\
\hline C $16: 1 w 7$ & Ácido palmitoléico & $1,98 a \pm 0,21$ & $1,56 a \pm 0,29$ & $1,61 \mathrm{a} \pm 0,30$ \\
\hline C $17: 1$ & Ácido heptadecenóico & $1,14 a, b \pm 0,32$ & $0,95 b \pm 0,13$ & $1,54 a \pm 0,14$ \\
\hline C 18:1w9 & Ácido oléico & $48,24 a \pm 1,43$ & $44,84 b \pm 1,57$ & $46,92 \mathrm{a}, \mathrm{b} \pm 1,14$ \\
\hline C 20:1w9 & Ácido gadoléico & $0,90 \mathrm{a} \pm 0,57$ & $0,96 a \pm 0,40$ & $0,76 a \pm 0,33$ \\
\hline Poliinsaturados & & $5,39 a, b \pm 0,64$ & $5,95 a \pm 0,59$ & $4,52 b \pm 0,70$ \\
\hline C $18: 2 w 6$ & Ácido linoléico & $5,24 a \pm 0,64$ & $5,53 a \pm 0,74$ & $3,81 b \pm 0,62$ \\
\hline C $18: 33$ & Ácido linolênico & $0,15 b \quad \pm 0,01$ & $0,42 \mathrm{a}, \mathrm{b} \pm 0,25$ & $0,71 \mathrm{a} \pm 0,10$ \\
\hline Insaturados & & $58,24 a \pm 2,00$ & $54,85 a \pm 1,70$ & $55,86 a \pm 1,46$ \\
\hline AGI/AGS & & $1,39 a \pm 0,51$ & $1,20 \mathrm{a} \pm 0,29$ & $1,26 a \pm 0,7$ \\
\hline AGPI/AGS & & $0,13 a \pm 0,06$ & $0,13 a \pm 0,06$ & $0,10 \mathrm{a} \pm 0,07$ \\
\hline
\end{tabular}

${ }^{1}$ Médias seguidas por letras diferentes nas linhas diferem entre si pelo teste de Tukey $(P<0,05)$

AGS: ácidos graxos saturados; AGMI: ácidos graxos monoinsaturados; AGPI: ácidos graxos poliinsaturados. 
aos reportados na literatura para carne caprina (Madruga et al., 2006a; Mahgoub et al., 2002; Rhee et al., 2000). No entanto, os valores de 0,10 a 0,13 (AGPI/AGS) foram inferiores aos demonstrados por Madruga et al. (2006a) e estiveram abaixo da recomendação de um limite mínimo de 0,4 (Wood et al., 2003).

O perfil aromático foi constituído de 11 classes de compostos químicos, totalizando 122 voláteis, entre eles, 37 hidrocarbonetos alifáticos, 34 alcoóis, 16 aldeídos, 12 hidrocarbonetos aromáticos, 9 cetonas, 7 terpenóides, 3 ésteres, 1 éter, 1 composto furano, 1 composto sulfurado e 1 lactona (Tabela 3). Todos os compostos identificados foram previamente citados no perfil aromático de carne cozida de caprinos (Madruga et al., 2003; Madruga et al., 2000) e de outras espécies de animais, principalmente em carne bovina e suína (Mottram 1991, 1998), e seus precursores e mecanismos de formação foram revistos em diversas publicações (Shahidi et al., 1986; MacLeod \& SeyyedainArdebili, 1981).

Em todos os extratos de voláteis obtidos das paletas caprinas, os hidrocarbonetos (alifáticos e aromáticos) apresentaram o maior somatório de abundância relativa (análise quantitativa) e foram seguidos pelos alcoóis e aldeídos, predominantes nos animais alimentados com $50 \%$ de concentrado. Hidrocarbonetos alifáticos, aldeídos, alcoóis e cetonas têm sido reportados freqüentemente como os principais voláteis do perfil aromático de carne cozida, portanto, sua abundância entre os voláteis da carne caprina já era previsível.

Observou-se predominância de voláteis nos extratos de carne de caprinos alimentados com a dieta com $50 \%$ de concentrado, na qual se identificou um total de 121 compostos. Alguns compostos de impacto aromático para a formação do aroma cárneo foram predominantes na carne dos animais alimentados com $50 \%$ de concentrado, como o maior número de aldeídos, compostos sulfurados, cetonas, alcoóis e hidrocarbonetos aromáticos.

O maior número e a abundância relativa de voláteis formados em extratos de caprinos alimentados com $50 \%$ de concentrado resultou provavelmente do fato de que a carne desses animais também apresentou maior teor de gordura. Madruga et al. (2003) encontraram maior abundância de voláteis em extratos de caprinos castrados, cuja carne apresentou maior percentual de gordura. A abundância de voláteis identificados na carne dos caprinos alimentados com 50\% de concentrado provavelmente contribuirá para um produto de melhor qualidade sensorial em comparação à carne obtida com os demais níveis de concentrado.
Tabela 3 - Voláteis da carne de cabritos Saanen alimentados com diferentes níveis de concentrado

\begin{tabular}{|c|c|c|c|}
\hline \multirow[b]{2}{*}{ Classes e número de voláteis ${ }^{3}$} & \multicolumn{3}{|c|}{ Nível de concentrado (\%) } \\
\hline & 80 & 65 & 50 \\
\hline \multicolumn{4}{|l|}{ Alcoóis (34) } \\
\hline Número total de voláteis & 28 & 17 & 34 \\
\hline Área total relativa (\%) & 22,27 & 10,79 & 14,50 \\
\hline \multicolumn{4}{|l|}{ Aldeídos (16) } \\
\hline Número total de voláteis & 15 & 10 & 15 \\
\hline Área total relativa (\%) & 14,01 & 4,43 & 19,48 \\
\hline \multicolumn{4}{|l|}{ Aromáticos (12) } \\
\hline Número total de voláteis & 11 & 10 & 12 \\
\hline Área total relativa (\%) & 28,93 & 44,38 & 34,90 \\
\hline \multicolumn{4}{|l|}{ Cetonas (9) } \\
\hline Número total de voláteis & 8 & 5 & 9 \\
\hline Área total relativa (\%) & 1,26 & 0,48 & 1,83 \\
\hline \multicolumn{4}{|l|}{ Ésteres (3) } \\
\hline Número total de voláteis & 3 & $\mathrm{ND}^{1}$ & 3 \\
\hline Área total relativa (\%) & 0,82 & $\mathrm{NQ}^{1}$ & 0,28 \\
\hline \multicolumn{4}{|l|}{ Éteres (1) } \\
\hline Número total de voláteis & 1 & ND & 1 \\
\hline Área total relativa (\%) & 0,10 & NQ & 0,04 \\
\hline \multicolumn{4}{|l|}{ Furanos (1) } \\
\hline Número total de voláteis & 1 & 1 & 1 \\
\hline Área total relativa (\%) & 0,23 & 0,10 & 0,23 \\
\hline \multicolumn{4}{|l|}{ Hidrocarbonetos (37) } \\
\hline Numero total de voláteis & 34 & 27 & 37 \\
\hline Área total relativa (\%) & 30,93 & 37,78 & 25,78 \\
\hline \multicolumn{4}{|l|}{ Lactonas (1) } \\
\hline Número total de voláteis & 1 & ND & 1 \\
\hline Área total relativa (\%) & 0,05 & NQ & 0,11 \\
\hline \multicolumn{4}{|l|}{ Sulfurados (1) } \\
\hline Numero total de voláteis & 1 & ND & 1 \\
\hline Área total relativa (\%) & 0,05 & NQ & 0,11 \\
\hline \multicolumn{4}{|l|}{ Terpenóides } \\
\hline Número total de voláteis & 7 & 7 & 7 \\
\hline Área total relativa (\%) & 0,84 & 2,05 & 2,14 \\
\hline Número total de compostos & 110 & 77 & 121 \\
\hline
\end{tabular}

${ }^{1}$ ND - Não-detectado; NQ - Não-quantificado.

2 Proporção Concentrado: Volumoso.

Segundo Sañudo et al. (1996), os concentrados determinam maior disponibilidade de energia na dieta, o que favorece a deposição de gordura na carcaça e na carne, no entanto, seu fornecimento em excesso diminui a digestão das fibras e, conseqüentemente, reduz o consumo de volumoso, elevando os custos de produção. Considerando os resultados obtidos neste estudo, recomenda-se para terminação de caprinos Saanen a relação volumoso:concentrado 50:50, visto que este nível promove menores custos de produção e carne com qualidade aromática e textura aceitável, 
teores de gorduras e percentuais de colesterol e ácidos graxos monoinsaturados, em especial o ácido oléico, compatíveis com as exigências do público consumidor.

\section{Conclusões}

A utilização de diferentes níveis de concentrado: volumoso na alimentação de caprinos Saanen influencia significativamente a concentração de gordura, o perfil de ácidos graxos mono e poliinsaturados, o perfil de voláteis e a textura da carne. Tanto na análise qualitativa quanto na análise quantitativa de voláteis, a carne de caprinos alimentados com $50 \%$ de concentrado e $50 \%$ de volumoso apresentou melhor qualidade aromática. Portanto, essa relação é a mais viável para a alimentação de caprinos machos Saanen para abate aos $22 \mathrm{~kg}$ de peso vivo, pois possibilita redução de custos e melhor qualidade química e aromática da carne caprina produzida.

\section{Agradecimento}

Ao CNPq e à CAPES, pelo apoio financeiro e pelas bolsas concedidas. Aos estudantes bolsistas do programa PIBIC UFPB/CNPq que contribuíram para a realização das análises de qualidade da carne e do manejo dos animais, em especial a Rejane G. da Silva (bolsista CFT) e Leila Santos de Melo (bolsista CFT).

\section{Literatura Citada}

ABULARACH, M.L.S.; ROCHA, C.E.; FELÍCIO P.E. Características de qualidade do contrafilé (m.L.dorsi) de touros jovens da raça Nelore. Ciência Tecnologia de Alimentos, v.18, n.2, p.205210, 1998.

AGRICULTURAL AND FOOD RESEARCH COUNCIL - AFRC. The nutrition of goats. Walhingford: CAB International, 1998. $115 p$

ALVES, K.S.; CARVALHO, F.F.R.; FERREIRA, M.A. et al. Níveis de energia em dieta para ovinos Santa Inês: características de carcaça e constituintes corporais. Revista Brasileira de Zootecnia, v.32, n.6, p.1927-1936, 2003.

ANON. Eight peak index of mass spectra. 3.ed. Aldermaston: MSDC, 1983.

ARRUDA, S.G.B. Perfil de ácidos graxos e qualidade da carne de caprinos da raça Saanen inteiros e castrados, com diferentes pesos ao abate. Recife: Universidade Federal de Pernambuco, 2003. 167p. Tese (Doutorado em Nutrição) Universidade Federal de Pernambuco, 2003.

ASSOCIATION OF OFFICIAL ANALITICAL CHEMISTS - AOAC. Official methods of analysis. 19.ed. Washington, D.C.: 2000. 1219p.

ATTI, N.; ROUISSI, H.; MAHOUACHI, M. The effect of dietary crude protein level on growth, carcass and meat composition of male goat kids in Tunisia. Small Ruminant Research, v.54, p.89-97, 2004.

BANSKALIEVA, V.; SAHLU, T.; GOETSCH, A.L. Fatty acid composition of goat muscles and fat depots - a review. Small Ruminant Research, v.37, p.255-268, 2000.
BICKERSTAFFE, R.; ROUISSI, H.; CHANG, M.W. et al. Consistency of tenderness in New Zealand retail meat. In: INTERNATIONAL CONGRESS OF MEAT SCIENCE AND TECHNOLOGY, 43. 1997, Auckland. Anais... Auckland, Nova Zelândia, 1997. p.196-197.

BOHAC, C.E.; RHEE, K.S.; ONO, K. Assessment of methodologies for colorimetric cholesterol assay of meats. Journal of Food Science, v.53, p.1642-1693, 1988.

BRASIL. MINISTÉRIO DA AGRICULTURA. Regulamento da Inspeção Industrial e Sanitária de Produtos de origem Animal. Brasília, DF: MA, 1997.

DUCKETT, S.K.; KLEIN, T.A.; LECKIE, R.K. et al. Effect of freezing on calpastatin activity and tenderness of callipyge lamb. Journal of Animal Science, v.76, n.7, p.1869-1874, 1998.

EGAN, H.; KIRK, R.S.; SAWYER, R. Pearson's chemical analysis of foods. 8.ed. London: Churchill Livingstone, 1981. 591p.

FOLCH, J.; FESS, M.; STANLEY, G.H. A simple method for isolation and purification of total lipids from animal tissues. The Journal of Biological Chemistry, v.226, n.1, p.497-509, 1957.

HEDRICK, H.B.; ABERLE, E.D.; FORREST, J.C. et al. Principles of meat science. 3.ed. Kendall: Hunt Publishing Company, 1994. p.292-293.

KESAVA RAO, V.; KOWALE, B.N.; VERMA, A.K. Effect of feeding water washed neem (Azadirachta indica) seed kernel cake on the quality, lipid profile and fatty acid composition of goat meat. Small Ruminant Research, v.22, p.1-7, 2003.

LIKENS, S.T.; NICKERSON, G.B. Detection of certain Hop oil constituents in brewing products, 1964, s.l.. Proceedings... s.l.: American Society Brewing Chemists, 1964. v.5, p.13-19.

MACLEOD, G.M.; SEYYEDAIN-ARDEBILI, M. Natural and simulated meat flavors (with particular reference to beef). Critical Review Food Science Nutrition, v.14, p.309-437, 1981.

MADRUGA, M.S. Fatores que afetam a qualidade da carne caprina e ovina. In: SIMPÓSIO INTERNACIONAL SOBRE CAPRINOS E OVINOS DE CORTE, 2., 2003, João Pessoa. Anais... João Pessoa: Empresa Estadual de Pesquisas Agropecuárias, 2003. p.417-423.

MADRUGA, M.S. Qualidade química, sensorial e aromática da carne caprina: verdades e mitos. In: ENCONTRO NACIONAL PARA O DESENVOLVIMENTO DA ESPECIE CAPRINA, 8., 2004, Botucatu. Anais... São Paulo: Universidade Estadual Paulista, Jaboticabal, 2004. p.215-234.

MADRUGA, M.S.; ARRUDA, S.G.B.; NASCIMENTO, J.A. Castration and slaughter age effects on nutritive value of the “mestiço" goat meat. Meat Science, v.52, p.119-125, 1999.

MADRUGA, M.S.; ARRUDA, S.G.B.; NARAIN, N. et al. Castration and slaughter age effects on panel assessment and aroma compounds of the "mestiço" goat meat. Meat Science, v.56, p.117-125, 2000.

MADRUGA, M.S.; NARAIN, N.; SOUZA, J.G. Castration and slaughter effects on fat components of "mestiço" goat meat. Small Ruminant Research, v.42, p.77-82, 2001.

MADRUGA, M.S.; SOUZA, J.G.; ARRUDA, S.G.B. et al. Carne Caprina de animais mestiços: estudos do perfil aromático. Ciência e Tecnologia de Alimentos, v.23, n.3, p.323-329, 2003.

MADRUGA, M.S.; RESOSEMITO, F.S.; NARAIN, N. et al. Effects on raising conditions of goats on Physico-chemical and chemical quality of its meat. Ciencia y Tecnologia de los Alimentos, v.5, n.2, p.100-104, 2006a.

MADRUGA, M.S.; ARAÚJO, W.O.; SOUSA, W.H. et al. Efeito do genótipo e do sexo sobre a composição química e o perfil de ácidos graxos da carne de cordeiros. Revista Brasileira de Zootecnia, v.35, n.4, p.1839-1844, 2006b.

MAHGOUB, O.; KHAN, A.J.; AL-MAQBALY, R.S. et al. Fatty acid composition of muscle and fat tissues of Omán Jebel Akhdar goats of different sexes and weights. Meat Science, v.61, p.381387, 2002. 
MATSUOKA, A.; FUROKAWA, N.; TAKAHASHI, T. Carcass traits and chemical composition of meat in male and female goats. Journal of Agriculture Science, v.68, p. 4421-4435, 1997.

MIOC, B.; PAVIC, V.; IVANKOVIC, A. Some carcass traits and chemical composition of different muscle groups in Alpine and Saanen breeds kids. Journal of Animal Science, v.46, p.8387, 2001.

MOTTRAM, D.S. Meat. In: MAARSE, H. (Ed.) Volatile compounds in foods and beverages. New York: Marcel Dekker, 1991. p.107-177.

MOTTRAM, D.S. Flavour formation in meat and meat products: a review. Food Chemistry, v.62, n.4, p.415-424, 1998.

NASSU, R.T.; BESERRA, F.J.; SOUSA, M.P. et al. Chemical composition of goat meat from Northeastern of Brazil slaughtered at different age. Pesquisa Agropecuaria Brasileira, v.64, p.1-4, 2002.

PARK, Y.W.; WASHINGTON, A.C. Fatty acid composition of goat organ and muscle meat of Alpine and Nubian breed. Journal Food Science, v.58, p.245-248, 1993.

PEREIRA FILHO, J.M.; RESENDE, K.T.; TEIXEIRA, I.A.M. et al. Efeito da restrição alimentar no desempenho produtivo e econômico de caprinos F1 Boer $\times$ Saanen. Revista Brasileira de Zootecnia, v.34, n.1, p.188-196, 2005.

RESENDE, F.D. Efeito do nível de fibra em detergente neutro da ração sobre a ingestão alimentar de bovídeos de diferentes grupos raciais, em regime de confinamento. Viçosa, MG: Universidade Federal de Viçosa, 1994. 60p. Tese (Doutorado em Zootecnia) - Universidade Federal de Viçosa, 1994.
RHEE, K.S.; WALDRON, D.F.; ZIPRIN, Y.A. et al. Fatty acids composition of goats diets versus intra muscular fat. Meat Science, v.54, p.313-318, 2000.

RHEE, K.S. Fatty acids in meats and meat products. In: CHOW, C.K. (Ed.). Fatty acids in foods and their health implications. New York: Marcel Dekker, 1992. p.65-93.

SANUDO, C.; SANTOLARIA, M.P.; MARIA G. et al. Influence of carcass weight on instrumental and sensory lamb meat quality in intensive production systems. Meat Science, v.42, p.195202, 1996

SHAHIDI, F.; RUBIN, L.J.; D’SOUZA, L.A. Meat flavor volatiles: a review of the composition, techniques of analysis, sensory evaluation. Critical Review Food Science Nutrition, v.24, p.141-243, 1986.

STATISTICAL ANALYSES SYSTEM - SAS. User's guide: statistics. 5.ed. Cary: SAS Institute, 1985. 956p.

TODARO, M.; CORRAO, A.; BARONE, C.M.A. et al. Use of weaning concentrate on the feeding of suckling kids: effects on meat quality. Small Ruminant Research, v.66, p.44-50, 2006.

PEREIRA, J.M.; RESENDE, K.T.; TEIXEIRA, I.A.M.D. et al. Effect of feed restriction on economical and productive performances of F1-Boer x Saanen goat. Revista Brasileira de Zootecnia, v.34, n.1, p.188-196, 2005.

WOOD, J.D.; RICHARDSON, G.R.; FISHER, A.V. et al. Effects of fatty acids on meat quality; a review. Meat Science, v.66, p.21-32, 2003.

ZAPATA, J.F.F.; NOGUEIRA, C.M.; SEABRA, L.M.J. et al. Características da carne de pequenos ruminantes do Nordeste do Brasil. Boletim SBCTA, v.37, n.2, p.146-153, 2003 